\title{
Determinan Permintaan Jasa Kesehatan BPJS (Studi Kasus: Puskesmas Wosi Kabupaten Manokwari)
}

\author{
Barce S. Kwando ${ }^{1}$, Yuyun P. Rahayu², Maria M. Semet ${ }^{3}$ \\ ${ }^{1}$ Alumni Jurusan Ekonomi Pembangunan, Universitas Papua \\ ${ }^{2,3}$ Dosen Ekonomi Pembangunan, Universitas Papua
}

\begin{abstract}
Abstrak
Tujuan penelitian ini adalah untuk mengetahui dan menganalisis pengaruh pendapatan, jumlah tanggungan, dan harga premi terhadap permintaan jasa pelayanan kesehatan BPJS kesehatan di Puskesmas Wosi, Distrik Manokwari Barat, Kabupaten Manokwari. Metode analisis yang digunakan adalah metode Analisis Deskriptif Kuantitatif dengan instrument pedoman wawancara dan kuesioner. Analisis data dilakukan dengan menggunakan alat analisis regresi linear berganda. Hasil penelitian menunjukan bahwa secara simultan variabel pendapatan, jumlah tanggungan, dan harga premi, berpengaruh signifikan sedangkan secara parsial hanya varibel jumlah tanggungan yang berpengaruh secara signifikan terhadap permintaan jasa pelayanan kesehatan BPJS di Puskesmas Wosi.
\end{abstract}

Kata kunci: permintaan jasa, pendapatan, jumlah tanggungan, harga premi

\begin{abstract}
Purpose of this study was to determine and analyze the effect of income, number of dependents, and premium prices on the demand for BPJS health services at Wosi Health Center, West Manokwari District, Manokwari Regency. The analytical method used is the quantitative descriptive analysis method with interview guides and questionnaires as instruments. Data analysis was performed using multiple linear regression analysis. The results showed that simultaneously the income variable, the number of dependents, and the premium price, had a significant effect, while partially only the number of dependents had a significant effect on the demand for BPJS health services at the Wosi Health Center.
\end{abstract}

Keywords: demand for services, income, number of dependents, premium price

How to Cite: Kwando, B.S., Rahayu, Y.P., Semet, M.M., (2021). Determinan Permintaan Jasa Kesehatan BPJS (Studi Kasus: Puskesmas Wosi Kabupaten Manokwari). JFRES: Journal of Fiscal and Regional Economy Studies, 4 (1), 15 - 22. 


\section{PENDAHULUAN}

Kesehatan merupakan salah satu aspek yang menentukan tinggi rendahnya standar hidup seseorang (Todaro, 2000). Oleh karena itu kesehatan menjadi hak dasar setiap orang, dan semua warga negara berhak mendapat pelayanan kesehatan termasuk masyarakat miskin. Pasal 34 ayat 2 menyebutkan bahwa negara mengembangkan sistem jaminan sosial bagi seluruh rakyat Indonesia (UUD 1945), yang pada hakekatnya jaminan kesehatan bertujuan untuk menjamin seluruh rakyat agar dapat memenuhi kebutuhan dasar hidup secara layak.

Untuk dapat memenuhi kebutuhan hidup dan menopang aktivitasnya manusia membutuhkan kesehatan yang baik/sehat, sehingga setiap individu akan berusaha mencapai status kesehatan tersebut dengan menginvestasikan dan atau mengkonsumsi sejumlah barang dan jasa kesehatan (Grossman, 1972). Kesehatan juga berkaitan erat dengan kualitas sumber daya manusia, sebab tinggi rendahnya kualitas sumber daya manusia (SDM) di tentukan oleh status kesehatan manusia itu sendiri. Dengan melihat pentingnya kesehatan maka pemerintah melakukan beberapa upaya untuk meningkatkan kemudahan akses pada fasilitas kesehatan, diantaranya adalah dengan menerbitkan undangundang no 40 tahun 2004 tentang Sistem Jaminan Nasional (UU SJSN) dan undang-undang no 24 tahun 2011 tentang Badan Penyelenggara Jaminan Sosial. Dengan terbitnya kedua undangundang dimaksud, Pemerintah diwajibkan untuk memberikan lima jaminan dasar bagi seluruh masyarakat Indonesia yaitu jaminan kesehatan, kecelakaan kerja, kematian, pensiun, dan tunjangan hari tua, dimana jaminan dimaksud akan dibiayai oleh perseorangan, pemberi kerja, dan/atau pemerintah. Dengan demikian, pemerintah akan mulai menerapkan kebijakan Universal Health Coverage dalam hal pemberian pelayanan kesehatan kepada seluruh masyarakat.

Agar pelayanan kesehatan ini dapat berjalan optimal pemerintah membentuk dua Badan Penyelenggara Jaminan Sosial (BPJS) yaitu BPJS Kesehatan dan BPJS Ketenagakerjaan. BPJS Kesehatan akan menyelenggarakan program jaminan kesehatan dan BPJS Ketenagakerjaan akan menyelenggarakan program jaminan atas kecelakaan kerja, kematian, pensiun dan hari tua. Secara eksplisit, UU SJSN menyatakan bahwa 4 (empat) BUMN di bidang asuransi yaitu PT. Jamsostek (Persero), PT. Taspen (Persero), PT.
Asabri (Persero), dan PT. Askes (Persero) akan ditransformasi menjadi BPJS. Berkaitan dengan institusi BPJS Kesehatan, UU BPJS secara jelas menyatakan bahwa PT. Askes (Persero) akan bertransformasi menjadi BPJS Kesehatan. Selanjutnya setelah diresmikannya BPJS pada tanggal 1 Januari 2014, maka semua program jaminan kesehatan yang diselenggarakan oleh Kementerian Kesehatan, Kementerian Pertahanan, Tentara Nasional Indonesia, Kepolisian Republik Indonesia, PT. Jamsostek (Persero), dan PT. Askes (Persero) akan diambil alih oleh BPJS Kesehatan dan premi bagi masyarakat miskin masih menjadi tanggungan pemerintah.

Kabupaten Manokwari merupakan salah satu kabupaten yang terletak di Provinsi Papua Barat dengan jumlah fasilitas kesehatan sebanyak 268 buah, yang tersebar di Sembilan distrik yaitu Distrik Manokwari Barat, Distrik Manokwari Timur, Manokwari Selatan, Manokwari Utara, Distrik Warmare, Distrik Prafi, Distrik Masni, Distrik Sidei, dan Distrik Tanah Rubuh. Dari total 268 fasilitas kesehatan yang tersebar di Kabupaten Manokwari diketahui terdapat 4 Rumah Sakit, 13 Puskesmas, 40 Polindes, 47 Puskesmas Pembantu, dan 164 Posyandu (BPS, 2017). Kabupaten Manokwari saat ini juga telah menggunakan Sistem Jaminan Sosial Nasional (BPJS) Badan Penyelenggara Jaminan Sosial, diketahui hingga tahun 2017 jumlah pengguna jasa kesehatan BPJS sebanyak 223.794 orang (pengguna Penerima Bantuan Iuran (PBI) dan Non Penerima Bantuan (Non-PBI)) (survei awal).

Puskesmas Wosi adalah satu dari 13 puskesmas yang berada di Distrik Manokwari Barat, Kabupaten Manokwari yang terletak di Jln. Drs Esau Sesa. Dari data yang diperoleh dari kantor BPJS Kabupaten Manokwari dan Puskesmas Wosi, pengguna jasa pelayanan kesehatan BPJS di Puskesmas Wosi pada tahun 2017 berjumlah 27.367 orang, dengan jumlah pengguna yang telah mengakses atau berobat di Puskesmas Wosi sebanyak 1.411 orang.

Dari tabel 1 dapat dilihat pengguna jasa kesehatan BPJS yang telah mengakses di Puskesmas Wosi terbagi menjadi 3 bagian yaitu pengguna BPJS penerima bantuan iuran (PBI) sebanyak 387 orang, pengguna BPJS non penerima bantuan iuran (Non PBI) sebanyak 556 orang, serta pengguna yang menggunakan kartu Indonesia sehat (KIS) yaitu sebanyak 468 orang. 
Tabel 1. Jumlah Pengguna Jasa Pelayanan Kesehatan BPJS Di Puskesmas Wosi, 2017

\begin{tabular}{clr}
\hline No & \multicolumn{1}{c}{ Keterangan } & Jumlah \\
\hline 1 & $\begin{array}{l}\text { Pengguna jasa kesehatan } \\
\text { BPJS }\end{array}$ & 27.367 \\
\hline 2 & $\begin{array}{l}\text { Pengguna BPJS yang telah } \\
\text { mengakses }\end{array}$ & \\
& $\begin{array}{l}\text { a) Pengguna BPJS Penerima } \\
\text { Bantuan Iuran }\end{array}$ & 387 \\
& $\begin{array}{l}\text { b) Pengguna BPJS Non } \\
\quad \text { Penerima Bantuan Iuran }\end{array}$ & 556 \\
& $\begin{array}{l}\text { c) Kartu Indonesia Sehat } \\
\text { (KIS) }\end{array}$ & 468 \\
\hline \multicolumn{2}{c}{ Total } & 1.411 \\
\hline
\end{tabular}

Sumber : BPJS Kabupaten Manokwari, 2017

Pada umumnya permintaan jasa pelayanan kesehatan BPJS dipengaruhi beberapa faktor termasuk faktor ekonomi. Salah satu yang mempengaruhi permintaan jasa pelayanan kesehatan adalah pendapatan. Pendapatan yang tinggi cenderung mendorong seseorang untuk berasuransi. Yang dimaksud pendapatan tinggi adalah seseorang yang mampu membiayai kebutuhan lain selain kebutuhan makan. Pendapatan memiliki hubungan yang positif dengan permintaan asuransi (Babbel, 1985; Susilowati \& Sem 2016).

Tinggi pendapatan seseorang bukan satu-satunya faktor yang mampu mendorong seseorang untuk berasuransi, selain pendapatan indikator lain yang mempengaruhi seseorang untuk berasuransi adalah jumlah tanggungan. Jumlah tanggungan di sini adalah tanggungan keluarga yang terdiri dari kepala keluarga, istri, dan anak. Adapun faktor lain yang bisa menambah jumlah tanggungan yaitu jika ada sanak saudara yang mungkin belum mampu hidup mandiri sehingga harus tinggal bersama. Semakin banyak jumlah tanggungan maka semakin besar pengeluaran yang harus dikeluarkan untuk memenuhi kebutuhan hidup. Menurut hasil penelitian yang di lakukan oleh (Atjih, 2017) menunjukan bahwa pendapatan dan jumlah tanggungan berpengaruh positif dan signifikan terhadap permintaan jasa pelayanan kesehatan BPJS.

Selain pendapatan dan jumlah tanggungan, harga premi merupakan salah satu faktor yang juga mempengaruhi permintaan seseorang terhadap barang atau jasa. Pada dasarnya bila harga komoditas pengganti lebih murah maka komoditas yang digantikannya akan mengalami pengurangan dalam permintaan. Munculnya barang pengganti yang lebih murah, kemungkinan besar akan mendorong sebagian besar konsumen untuk memilih barang substitusi tersebut (Sugiarto, 2005). Harga menjadi sangat penting dalam berasuransi karena seseorang harus memperhitungkan pendapatan dan pengeluarannya apakah mampu memenuhi kebutuhan sehari-hari atau tidak. Bila pendapatan kurang maka seseorang akan mengasuransikan diri dan keluarganya ditempat lain yang sesuai dengan keuangannya. Menurut hasil penelitian yang dilakukan oleh (Arsyad, 2015) di rumah sakit umum (Haji Padjonga Daeng Ngalle) Kabupaten Takalar menunjukan bahwa biaya kunjungan dan harga obat berpengaruh signifikan terhadap permintaan jasa pelayanan kesehatan BPJS.

Hasil penelitian Parung (2014) juga menemukan faktor-faktor yang signifikan mempengaruhi antara lain pendapatan, harga kunjungan, jarak, dan harga obat alternatif terhadap frekuensi kunjungan ke layanan kesehatan. Tetapi penelitian ini lebih ke layanan kesehatan secara umum dan bukan layanan kesehatan khusus BPJS.

Berdasarkan uraian diatas pendapatan, jumlah tanggungan, dan harga iuran merupakan faktor yang diduga mempengaruhi permintaan jasa pelayanan kesehatan BPJS di Puskesmas Wosi. Dengan demikian penelitian ini bertujuan untuk mengetahui dan menganalisis pengaruh pengaruh pendapatan, jumlah tanggungan, dan harga premi terhadap permintaan jasa pelayanan kesehatan BPJS kesehatan di Puskesmas Wosi.

\section{METODE PENELITIAN}

Penelitian ini merupakan penelitian dengan pendekatan kuantitatif. populasi adalah seluruh pengguna jasa pelayanan kesehatan BPJS di Puskesmas Wosi. Jumlah populasi sebanyak 1.411 orang pengguna jasa pelayanan kesehatan BPJS puskesmas wosi (Puskesmas Wosi, 2017). Rumus Slovin digunakan untuk menentukan jumlah sampel penelitian ini sebagai berikut (Sevilla, 1993):

Keterangan :

$$
\mathrm{n}=\frac{N}{1+N(e)^{2}}
$$

$\mathrm{n}=$ jumlah sampel

$\mathrm{N}=$ jumlah populasi

$\mathrm{e}^{2}=$ batas toleransi kesalahan, yaitu $10 \%(0,1)$

$$
\mathrm{n}=\frac{1.411}{1+1.411(0,1)^{2}}=\frac{1.411}{1+14,11}
$$


$\mathrm{n}=\frac{1.411}{15,11}=93,38 \approx 93$

Jumlah sampel yang akan di ambil dalam penelitian ini adalah 93 orang responden bukan penerima bantuan iuran (non-PBI).

Variabel dependen dalam penelitian ini adalah Permintaan Jasa Pelayanan Kesehatan BPJS. Variabel independennya pendapatan, jumlah tanggungan dan harga premi.

Analisis regresi berganda digunakan untuk mengetahui seberapa besar pengaruh pendapatan, jumlah tanggungan dan harga terhadap permintaan jasa pelayanan kesehatan BPJS. Model persamaan regresi berganda tersebut dapat di rumuskan sebagai berikut:

$Y=\beta_{0}+\beta_{1} X_{1}+\beta_{2} X_{2}+\beta_{3} X_{3}+e$

Dimana:

$\mathrm{Y}=$ Permintaan Jasa Pelayanan Kesehatan BPJS

$\mathrm{X}_{1}=$ Pendapatan (rupiah/bulan)

$\mathrm{X}_{2}=$ Jumlah Tanggungan (orang/keluarga)

$\mathrm{X}_{3}=$ Harga premi (rupiah/bulan)

$\beta_{0}=$ Konstan

$\beta_{1}, \beta_{2}, \beta_{3}$, = koefisien regresi

$\mathrm{e}=$ residual

Persamaan regresi yang terbentuk diatas untuk menguji hipotesis penelitian sebagai berikut:

$\mathrm{H}_{\mathrm{o}}$ : Variabel pendapatan, jumlah tanggungan dan harga Premi tidak berpengaruh terhadap variabel permintaan jasa pelayanan kesehatan BPJS.
$\mathrm{H}_{1}$ : Variabel pendapatan, jumlah tanggungan dan harga Premi berpengaruh terhadap variabel permintaan jasa pelayanan kesehatan BPJS.

Definisi operasional masing-masing variabel yaitu:

1. Permintaan jasa pelayanan kesehatan

Permintaan Jasa pelayanan kesehatan BPJS adalah jumlah pengguna jasa kesehatan BPJS yang telah mengakses pelayanan kesehatan BPJS bukan penerima bantuan iuran di Puskesmas Wosi, satuan ukur yang digunakan adalah jumlah orang dalam keluaga yang telah mengakses pertahun.

2. Pendapatan

Pendapatan adalah seluruh pendapatan yang diterima oleh individu baik dari pendapatan utama, sampingan dan lainnya, satuan yang digunakan untuk mengukur pendapatan adalah rupiah perbulan.

3. Jumlah Tanggungan

Jumlah tanggungan adalah jumlah orang yang menjadi tanggungan dalam keluarga yang terdiri dari kepala keluarga, istri, dan anak, satuan yang digunakan adalah jumlah orang perkeluarga.

4. Harga Premi

Harga merupakan biaya iuran yang harus dikeluarkan oleh pengguna jasa pelayanan kesehatan BPJS, satuan yang digunakan untuk mengukur adalah rupiah perbulan perjumlah anggota keluarga.

Tabel 2. Karakteristik Responden Berdasarkan Usia, Jenis Kelamin Dan Pendidikan Terakhir

\begin{tabular}{|c|c|c|c|c|c|c|}
\hline \multirow{4}{*}{ A } & \multirow{4}{*}{$\begin{array}{l}\text { Kategori } \\
\text { Usia (tahun) }\end{array}$} & \multicolumn{4}{|c|}{ Jumlah } & \multirow{4}{*}{$\begin{array}{c}\text { Total } \\
\text { (Persentase) }\end{array}$} \\
\hline & & \multicolumn{4}{|c|}{ Jenis Kelamin } & \\
\hline & & \multicolumn{2}{|c|}{ Laki-laki } & \multicolumn{2}{|c|}{ Perempuan } & \\
\hline & & Jumlah & Persentase & Jumlah & Persentase & \\
\hline 1 & $20-30$ & 40 & 43 & 16 & 18 & $56(61 \%)$ \\
\hline 2 & $30-40$ & 10 & 11 & 5 & 5 & $15(16 \%)$ \\
\hline 3 & $41-50$ & 10 & 11 & 5 & 5 & $15(16 \%)$ \\
\hline \multirow[t]{2}{*}{4} & $51-70$ & 7 & 7 & 0 & 0 & $7(7 \%)$ \\
\hline & Total & 66 & 72 & 27 & 28 & $93(100 \%)$ \\
\hline \multicolumn{7}{|c|}{ B $\quad$ Pendidikan Terakhir } \\
\hline 1 & SD & 4 & 4 & 1 & 1 & $5(5 \%)$ \\
\hline 2 & SMP & 17 & 18 & 6 & 7 & $23(25 \%)$ \\
\hline 3 & SMA & 41 & 44 & 16 & 17 & $57(61 \%)$ \\
\hline \multirow[t]{2}{*}{4} & S1/DIPLOMA & 4 & 4,5 & 4 & 4,5 & $8(9 \%)$ \\
\hline & Total & 66 & 70,5 & 27 & $29,5 \%$ & $93(100 \%)$ \\
\hline
\end{tabular}

Sumber : Data primer diolah, 2018

\section{HASIL PENELITIAN}

Peserta pengguna jasa pelayanan kesehatan BPJS terbanyak untuk laki-laki dan perempuan berada pada usia 20-30 tahun dengan jumlah laki-laki sebanyak 40 orang dan perempuan sebanyak 17 orang. Sedangkan peserta penggguna jasa pelayanan kesehatan BPJS yang paling sedikit untuk laki-laki dan perempuan berada pada usia 
51 tahun ke atas dengan jumlah laki-laki sebanyak 7 orang dan perempuan tidak ada.

Berdasarkan tabel 2 dapat disimpulkan bahwa pendidikan terakhir peserta pengguna jasa pelayanan kesehatan BPJS terbanyak untuk lakilaki dan perempuan berada pada tingkat SMA dengan jumlah laki-laki sebanyak 41 orang dan perempuan 16 orang. Sedangkan peserta penggguna jasa pelayanan kesehatan BPJS yang paling sedikit untuk laki-laki dan prempuan berada pada tingkat pendidikan terakhir SD dengan jumlah laki-laki sebanyak 4 orang dan perempuan 1 orang. Ini menunjukan bahwa tingkat pendidikan cukup berpengaruh terhadap permintaan asuransi kesehatan, sehingga mereka yang berpendidikan terakhir SMA yang paham dengan pentingnya kesehatan menjaminkan diri pada asuransi kesehatan BPJS.

\section{Statistik Deskriptif}

Variabel dependen dalam penelitian ini adalah permintaan jasa pelayanan kesehatan BPJS. Sedangkan, variabel independen dalam penelitian ini adalah pendapatan, jumlanh tanggungan, dan harga premi. Nilai rata-rata dari keempat variabel tersebut di sajikan pada tabel 3 .

Tabel 3. Statistik Deskriptif

\begin{tabular}{lrrr}
\hline \multicolumn{1}{c}{ Variabel } & Minimum & \multicolumn{1}{c}{ Maximum } & \multicolumn{1}{c}{ Mean } \\
\hline Permintaan BPJS (orang) & 1,00 & 7,00 & 2,14 \\
\hline Pendapatan (Rp/bulan) & $500.000,00$ & $10.000 .000,00$ & $2.302 .150,54$ \\
\hline Jumlah Tanggungan (Orang/Keluarga) & 1,00 & 5,00 & 2,30 \\
\hline Harga Premi (Rp/Bulan) & $26.000,00$ & $81.000,00$ & $31.688,17$ \\
\hline
\end{tabular}

\section{Sumber : Data primer diolah, 2018}

Berdasarkan tabel 3 dapat dijelaskan bahwa permintaan jasa pelayanan kesehatan BPJS memiliki rata-rata permintaan pengguna sebanyak 2 orang pengguna dengan nilai mean 2,30 . Hal ini menggambarkan bahwa rata-rata dalam setahun ada 2 orang dalam setiap keluarga yang mengakses jasa pelayanan kesehatan BPJS di puskesmas Wosi.

Untuk variabel pendapatan, peserta jasa pelayanan kesehatan BPJS memiliki pendapatan yang berbeda-beda. Dilihat dari nilai mean pendapatan pada tabel 3 sebesar Rp 2.302.150,54. Hal ini disebabkan karena jenis pekerjaan dari peserta jasa BPJS yang berbeda-beda sehingga pendapatan peserta juga berbeda-beda.

Jika dilihat dari variabel jumlah tanggungan, peserta jasa pelayanan kesehatan BPJS memiliki nilai mean jumlah tanggungan 2,30. Ini disebabkan karena jumlah tanggungan atau orang dalam setiap keluarga berbeda-beda, ada yang belum berkeluarga, ada yang sudah berkeluarga dan ada yang sudah berkeluarga serta memiki anak. Sedangkan untuk variabel harga premi, nilai mean yang diperoleh dari peserta pengguna jasa pelayanan kesehatan BPJS adalah Rp $31.688,17$. Hal ini menunjukan bahwa pemilihan kelas BPJS dari setiap peserta tidak semuanya sama ada yang memilih kelas 1, 2,dan 3 tergantung dari kepuasan peserta itu sendiri.

\section{Pengujian Hipotesis}

Uji t (Parsial)
Uji $\mathrm{t}$ digunakan untuk mengetahui apakah variabel-variabel independen secara parsial berpengaruh nyata atau tidak terhadap variabel dependen. Derajat signifikansi yang digunakan adalah 5\% (0,05). Kriteria pengujian uji statistik t adalah Jika t signifikan $>5 \%$ maka variabel bebas (X) tidak berpengaruh signifikan terhadap variabel terikat (Y) tetapi Jika t signifikan $<5 \%$ maka variabel bebas $(\mathrm{X})$ berpengaruh signifikan terhadap variabel terikat $(\mathrm{Y})$.

Nilai signifikansi lebih besar dari probabilitas 0,05 atau nilai 0,868>0,05 (tabel 5), maka $\mathrm{H}_{1}$ ditolak dan $\mathrm{H}_{0}$ diterima sehingga hipotesis yang menyatakan ada pengaruh yang signifikan antara pendapatan $\left(\mathrm{X}_{1}\right)$ secara persial terhadap permintaan jasa pelayanan kesehatan BPJS (Y) tidak dapat diterima. Dapat disimpulkan bahwa variabel pendapatan $\left(\mathrm{X}_{1}\right)$ tidak berpengaruh signifikan terhadap variabel terikat permintaan jasa pelayanan kesehatan BPJS (Y) pada alpha $5 \%$.

Selanjutnya, nilai signifikansi lebih kecil dari probabilitas 0,05 atau nilai $0,000<0,05$, maka $\mathrm{H}_{1}$ diterima maka dan $\mathrm{H}_{0}$ ditolak sehingga hipotesis yang menyatakan ada pengaruh yang signifikan antara jumlah tanggungan $\left(\mathrm{X}_{2}\right)$ secara persial terhadap permintaan jasa pelayanan kesehatan BPJS (Y) dapat diterima. Dapat disimpulkan bahwa variabel jumlah tanggunan $\left(\mathrm{X}_{2}\right)$ berpengaruh signifikan terhadap variabel terikat permintaan jasa pelayanan kesehatan BPJS (Y) pada alpha $5 \%$. 
Nilai signifikansi lebih besar dari probabilitas 0,05 atau nilai $0,295>0,05$, maka $\mathrm{H}_{1}$ ditolak dan $\mathrm{H}_{0}$ diterima sehingga hipotesis yang menyatakan ada pengaruh yang signifikan antara harga premi $\left(\mathrm{X}_{3}\right)$ secara persial terhadap permintaan jasa pelayanan kesehatan BPJS (Y) tidak dapat diterima. Dapat disimpulkan bahwa variabel harga premi $\left(\mathrm{X}_{3}\right)$ tidak berpengaruh signifikan terhadap variabel terikat permintaan jasa pelayanan kesehatan BPJS (Y) pada alpha $5 \%$.

\section{Uji Signifikansi F (Simultan)}

Tabel 4 menyajikan hasil dari uji f pada variabel bebas terhadap variabel terikat. Dari hasil uji F diperoleh nilai signifikan lebih kecil dari nilai probabilitas 0,05 atau nilai $0,000<0,05$; maka $\mathrm{H}_{1}$ diterima dan $\mathrm{H}_{0}$ ditolak, berarti secara bersamasama (simultan), variabel pendapatan, jumlah tanggungan, dan harga premi berpengaruh signifikan terhadap permintaan jasa pelayanan kesehatan BPJS di Puskesmas Wosi.

Tabel 4. ANOVA

\begin{tabular}{llllll}
\hline \multicolumn{1}{c}{ Model } & \multicolumn{1}{c}{$\begin{array}{c}\text { Sum of } \\
\text { Squares }\end{array}$} & \multicolumn{1}{c}{$\begin{array}{c}\text { Mean } \\
\text { Square }\end{array}$} & F & Sig. \\
\hline Regression & 77.928 & 3 & 25.976 & 23.951 & $0.000^{\mathrm{b}}$ \\
Residual & 96.523 & 89 & 1.085 & & \\
Total & 174.452 & 92 & & & \\
\hline
\end{tabular}

Sumber : Data primer diolah, 2018

Dari hasil analisis regresi yang telah dilakukan diperoleh koefisian regresi, nilai hitung dan signifikansi seperti disajikan pada tabel 5 .

Tabel 5. Coefficients

\begin{tabular}{lrrrrr}
\hline \multicolumn{1}{c}{ Model } & \multicolumn{2}{c}{$\begin{array}{c}\text { Unstandardized } \\
\text { Coefficients }\end{array}$} & $\begin{array}{c}\text { Standardized } \\
\text { Coefficients }\end{array}$ & T & Sig. \\
\cline { 2 - 4 } & \multicolumn{1}{c}{ B } & \multicolumn{1}{c}{ Std. Error } & \multicolumn{1}{c}{ Beta } & & \\
\hline (Constant) & 0.537 & 0.269 & & 1.992 & 0.049 \\
Pendapatan (juta Rp/bulan) & 0.016 & 0.095 & 0.016 & 0.166 & 0.868 \\
Jumlah Tanggungan (Orang/keluarga) & 0.862 & 0.143 & 0.774 & 6.045 & 0.000 \\
Harga (Ratusan Ribu Rp/bulan) & -0.491 & 0.466 & -0.151 & -1.054 & 0.295 \\
\hline
\end{tabular}

\section{Sumber : Data primer diolah, 2018}

Dari hasil uji analisis regresi tersebut jika ditulis persamaan regresi sebagai berikut :

Permintaan $(\mathrm{Y})=0,537+0,16 \mathrm{X}_{1}+0,862 \mathrm{X}_{2}-$ $0,491 X_{3}$

Keterangan :

$\mathrm{Y}=$ permintaan jasa pelayanan kesehatan BPJS

$\mathrm{X}_{1}=$ pendapatan

$\mathrm{X}_{2}=$ jumlah tanggungan

$\mathrm{X}_{3}=$ harga premi

Diduga pendapatan, jumlah tanggungan, dan harga premi berpengaruh terhadap permintaan jasa pelayanan kesehatan BPJS. Untuk mengetahui ada tidaknya pengaruh dari ketiga variabel independen tersebut maka di analisis menggunakan analisis regresi linier berganda. Secara lengkap pengaruh pendapatan, jumlah tanggungan, dan harga premi terhadap permintaan jasa pelayanan kesehatan BPJS di puskesmas wosi dapat dilihat pada tabel 5 .

Dari persamaan model regresi tersebut, maka dapat dijelaskan bahwa :

1. Ketika variabel pendapatan, jumlah tanggungan, dan harga premi bernilai konstan atau nol, maka jumlah kunjungan peserta pengguna jasa pelayanan kesehatan BPJS adalah 0,53 atau dengan kata lain tidak ada pengguna yang mengakses jasa BPJS

2. Koefisien dari variabel pendapatan dalam persamaan regresi berganda bernilai 0,16 , hal ini menunjukan bahwa setiap kenaikan RP 1.000.000,- pendapatan maka akan meningkatkan jumlah permintaan jasa pelayanan kesehatan BPJS sebanyak 0,16. Namun karena variabel pendaptan memiliki nilai yang tidak signifikan, sehingga dinyatakan variabel pendapatan tidak memiliki pengaruh terhadap permintaan jasa pelayanan kesehatan BPJS. Dapat dijelaskan bahwa tinggi rendahnya pendapatan tidak mempengaruhi seseorang untuk mengasuransikan dirinya pada asuransi kesehatan BPJS. Hasil penelitian ini sejalan dengan penelitian yang dilakukan oleh Arsyad (2015) yang menunjukan bahwa pendapatan tidak berpengaruh signifikan terhadap permintaan jasa pelayanan kesehatan BPJS. Namun tidak sejalan penilitian yang dilakukan oleh oleh Parung (2015) dan Atjih (2017) yang menunjukan bahwa pendapatan berpengaruh positif dan signifikan terhadap permintaan jasa pelayanan kesehatan BPJS. 
3. Koefisien dari variabel jumlah tanggungan dalam persamaan regresi berganda bernilai 0,862 . Hal ini menunjukan bahwa setiap kenaikan 1 orang jumlah tanggungan keluarga maka akan meningkatkan jumlah permintaan jasa pelayanan kesehatan BPJS sebanyak 1 kali. Hal ini berarti bahwa ketika jumlah tanggungan keluarga meningkat maka kepala keluarga harus bertanggung jawab untuk memenuhi seluruh kebutuhan keluarga termasuk pengeluaran untuk kebutuhan asuransi kesehatan, dengan demikian maka permintaan untuk jasa pelayanan kesehatan BPJS akan meningkat.

Dari gambar 1 dapat dilihat bahwa ketika jumlah tanggungan keluarga meningkat maka permintaan jasa pelayanan kesehatan BPJS ikut meningkat. Ini menunjukan bahwa kesadaran masyarakat akan pentingnya kesehatan semakin besar, sehingga dapat dikatakan permintaan jasa pelayanan kesehatan BPJS adalah bagian dari kebutuhan. Hasil penelitian ini sejalan dengan penelitian yang dilakukan oleh Atjih (2017) yang menyatakan bahwa jumlah tanggungan berpengaruh positif dan signifikan terhadap permintaan jasa pelayanan kesehatan BPJS.

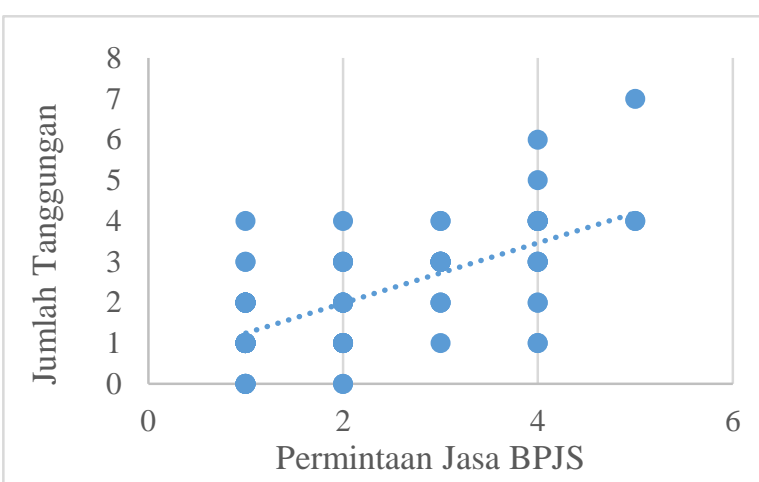

Sumber : Data primer diolah, 2018

Gambar 1. Kurva Jumlah Tanggungan

4. Koefisien dari variabel harga premi dalam persamaan regresi berganda bernilai negatif sebesar 0,491. Hal ini menunjukan bahwa setiap kenaikan Rp 100.000,- untuk harga premi maka akan menurunkan jumlah permintaan jasa pelayanan kesehatan BPJS sebanyak 1 orang. Hal ini sesuai dengan teori permintaan bahwa ketika harga suatu komoditas barang atau jasa meningkat maka permintaan akan komoditas tersebut menurun. Dari hasil SPSS variabel harga premi memiliki nilai yang tidak signifikan, sehingga dinyatakan variabel harga premi tidak memiliki pengaruh terhadap permintaan jasa pelayanan kesehatan BPJS.

Dari gambar 2 dapat dilihat bahwa ketika harga premi meningkat maka permintaan terhadap jasa pelayanan kesehatan BPJS akan menurun, menurut Samuelson \& Nordhaus (1992) menyebutkan bahwa seseorang dalam usaha memenuhi kebutuhannya, pertama kali yang akan dilakukan adalah pemilihan atas berbagai barang dan jasa yang dibutuhkan, selain itu juga dilihat apakah harganya sesuai kemampuan yang dimiliki. Jika harga tidak sesuai, maka ia akan memilih barang dan jasa lain yang sesuai dengan kemampuan yang dimilikinya. Karena permintaan kesehatan yang efektif akan terjadi ketika konsumen memiliki kesediaan (willingness) dan kemampuan (ability) untuk membeli atau membayar sejumlah jenis pelayanan kesehatan yang diperlukan (Grossman, 1972).

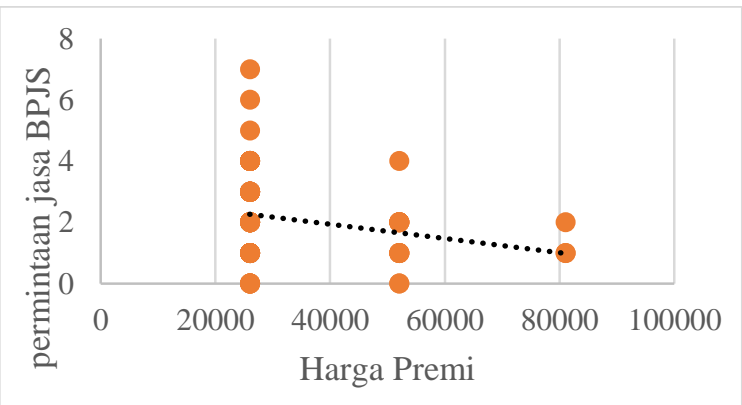

Sumber : Data primer diolah, 2018

Gambar 2. Kurva Harga Premi KESIMPULAN

Berdasarkan hasil dan pembahasan penelitian dapat disimpulkan bahwa variabel jumlah tanggungan berpengaruh signifikan, sehingga hipotesis yang menyatakan ada pengaruh yang signifikan antara jumlah tanggungan secara persial terhadap permintaan jasa pelayanan kesehatan BPJS dapat diterima pada taraf kepercayaan $5 \%$. Sedangakan variabel pendapatan dan harga premi tidak berpengaruh signifikan, sehingga hipotesis yang menyatakan ada pengaruh yang signifikan antara pendapatan dan harga premi secara parsial terhadap permintaan jasa pelayanan kesehatan BPJS tidak dapat diterima pada taraf kepercayaan $5 \%$.

Selanjutnya simultan, variabel pendapatan, jumlah tanggungan dan harga premi mempunyai pengaruh signifikan terhadap permintaan jasa pelayanan kesehatan BPJS pada taraf signifikan 
5\% (0,05). Dengan demikian secara bersamasama (simultan), variabel pendapatan, jumlah tanggungan, dan harga premi berpengaruh signifikan terhadap permintaan jasa pelayanan kesehatan BPJS. Jika dilihat dari nilai $\mathrm{R}^{2}$ sebesar 0,447 , maka dalam penelitian ini permintaan jasa pelayanan kesehatan BPJS dapat dijelaskan oleh variasi dari variabel pendapatan, jumlah tanggungan, dan harga premi sebesar 44,7\%, sedangkan sisanya $(100 \%-44,7 \%=55,3 \%)$ di jelaskan oleh variabel lain diluar model ini.

\section{DAFTAR PUSTAKA}

Arsyad, Ayu F. 2015. Analisis Permintaan Jasa Pelayanan Kesehatan Khusus BPJS Rumah Sakit Umum (Haji Padjonga Daeng Ngalle) Di Kabupaten Takalar.

Atjih, Kevin T. 2017. Analisis Faktor-Faktor Yang Mempengaruhi Permintaan Asuransi BPJS Kesehatan Untuk Non Pns Di Kota Makassar.

Babbel, D. F. 1985. The Price Elasticity of Demand for Whole Life Insurance, The Journal of Finance, vol. 40, no. 1, pp. 225-239.

Badan Penyelenggara Jaminan Sosial (BPJS) Kesehatan. 2017. Jumlah Pengguna BPJS Di Puskesmas Wosi.

Badan Pusat Statistik. 2017, "Kabupaten Manokwari Dalam Angka". Penerbit: BPS Kabupaten Manokwari.
Grossman, Michael. 1972. On The Concept Of Health Capital And Demand For Health. Journal Political Economic. Vol. 80.

Parung, Jennyfer M. A. 2014. Analisis Permintaan Jasa Pelayanan Kesehatan Di Kabupaten Toraja Utara.

Puskesmas Wosi. 2017. Jumlah Peserta Pengguna Jasa BPJS Di Puskesmas Wosi.

Samuelson, Paul A dan Nordhaus, William D. 1992. Makro Ekonomi, Edisi Terjemahan, Edisi 4, Penerbit: Erlangga Jakarta.

Sugiarto, dkk. 2005. Ekonomi Mikro. Jakarta : PT Gramedia Pustaka Utama.

Susilowati, F., \& Sem, S. 2016. Analisis Permintaan Asuransi Di Daerah Istimewa Yogyakarta. Universitas PGRI Yogyakarta.

Todaro, P Michael. 2000. Pembangunan Ekonomi di Dunia Ke-3 Jilid 1. Jakarta Penerbit Erlangga.

Undang-Undang Dasar Republik Indonesia. 1945. Tentang Penyelenggara Jaminan Sosial.

Undang-Undang Dasar Republik Indonesia. 2004. Tentang Sistem Jaminan Nasional (UU SJSN).

Undang-Undang Republik Indonesia. 2011. Tentang Badan Penyelenggara Jaminan Sosial (BPJS). 